\title{
Glide path preparation in Endodontics: case report and a literature review of available materials and techniques
}

SADJ April 2019, Vol. 74 No. 3 p129 - p136

PJ van der Vyver', ${ }^{1}$ M Vorster ${ }^{2}$, F Paleker ${ }^{3}$, FA de Wet ${ }^{4}$

\begin{abstract}
Maintaining a smooth, reproducible, glide path when successive files are used is an important characteristic of proper root canal preparation. Glide path enlargement allows for safer, more effective canal shaping with increased prospects of successful treatment outcomes.

Many authors have proposed that rotary nickel titanium (NiTi) instruments should not be used for canal preparation without prior glide path preparation. In this paper the authors discuss a review of the literature on some of these glide path techniques and illustrate the correct clinical application of some of these preparation techniques through clinical case studies.
\end{abstract}

\section{INTRODUCTION}

The endodontic glide path is defined as a smooth, patent passage from the coronal orifice of the canal to the radiographic terminus or electronically determined portal of exit. ${ }^{1}$ A successful glide path is an uninterrupted passage that can be reproduced when small-size files are used in sequence in the canal. ${ }^{2}$ Apical pre-enlargement tends to minimise biomechanical preparation failures such as canal transportation and ledge formation at different levels and also reduces the number of pecking motions required to achieve the working length. ${ }^{3,4}$

The glide path can be achieved with both hand - and rotary instruments. ${ }^{5}$ The use of hand files, however, has been shown to be more time consuming, particularly in teeth with constricted and/or severely curved canals. ${ }^{6}$ Over the last few years, research has repeatedly shown that $\mathrm{NiTi}$ glide path rotary instruments are capable of achieving a safe and predictable glide path in comparison with hand files. ${ }^{5-8}$

Author affiliations:

1. Peet van der Vyver: BChD, PG Dip Dent (Endo), PG Dip Dent (Aesthet Dent), MSc, PhD (Pret), Department of Odontology, School of Dentistry, University of Pretoria, Pretoria, South Africa and Private Practice, Sandton, South Africa.

2. Martin Vorster: BChD (Pret), PG Dip Dent (Endo), MSc (Pret), Department of Odontology, School of Dentistry, University of Pretoria, Pretoria, South Africa.

3. Farzana Paleker: BChD (Stell), Dip Odont (Endo), MSc (Pret), Department of Odontology, School of Dentistry, University of Pretoria, Pretoria, South Africa.

4. FA de Wet: BChD, MSc, DSc (Pret), Department of Odontology, School of Dentistry, University of Pretoria, Pretoria, South Africa.

Corresponding author: $\mathrm{PJ}$ van der Vyver

Tel: +27 (0)117811020 Email: peetv@iafrica.com
Mechanical (NiTi) glide path systems have been shown to improve the glide path prior to the use of NiTi shaping instruments. ${ }^{9,10}$ Systems like the ProGlider (Dentsply Sirona, Ballaigues, Switzerland), and G-Files (Micro-Mega, Besançon, France) are said to preserve the original canal anatomy and cause fewer aberrations and modifications of canal curvature.

Predictable radicular cleaning and shaping is more likely after an established glide path has been formed that is smooth and centred from the root canal orifice to the physiologic terminus. Glide path enlargement allows for more effective and safer rotary shaping because it guarantees that the root canal diameter is sufficiently large to receive the first shaping instrument. ${ }^{11-13}$

A number of studies have illustrated the many benefits of glide path formation, which include decreased canal aberrations and decreased risk of shaping file fracture. ${ }^{11,12,14,15}$ According to West, a successful glide path will most likely be maintained by larger shaping instruments, and must then be the starting point of all root canal treatment. ${ }^{16}$ The converse, therefore, follows: procedural errors initiated during glide path enlargement are more likely to be exacerbated during shaping by larger NiTi rotary files, in this way affecting the clinical outcome. Any instrumentation that removes excessive dentine and changes the canal anatomy significantly will cause iatrogenic preparation errors and may adversely affect the strength of the tooth. ${ }^{17,18}$

\section{Stainless steel K-Files Manual}

According to West, a glide path is present when a size 10 stainless- steel K-File fits loosely in the canal. ${ }^{16}$ Stainless steel K-Files (Fig. 1) have a constant taper of $2 \%$. West advocates using these files in a vertical in-and-out motion with initial amplitudes of $1 \mathrm{~mm}$, gradually increasing as the dentine wall wears away and the file advances apically. West stresses that the file must not be forced apically through any obstructions and suggests oscillating the file back and forth in $30^{\circ}$ to $60^{\circ}$ increments to simulate a "watch-winding" motion to remove restrictive dentine in narrow canals.

Van der Vyver recommends that the file be withdrawn in $1 \mathrm{~mm}$ increments from $1 \mathrm{~mm}$ to $5 \mathrm{~mm}$, while ensuring that the file may continue to slide to working length, confirming the glide path after each increment. ${ }^{19}$ 


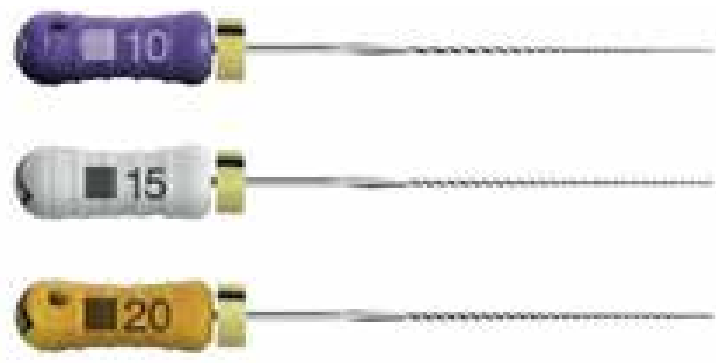

Figure 1. Stainless steel K-Files sizes 10 (purple), 15 (white) and 20 (yellow).

Schilder recommended pre-curving instruments for use in curved canals. This technique allows the "watchwinding" motion in order to create space for larger curved files to follow by advancing the file just short of maximum resistance. ${ }^{20}$ Then the file is removed while simultaneously being rotated in a clockwise direction. The many advantages of using stainless steel K-Files over NiTi files for glide path enlargement include improved tactile sensation with a heightened appreciation of anatomical curvatures; decreased risk of file fracture and decreased cost; and the elimination of the use of a hand piece. ${ }^{11,21-23}$ Canal obstructions can be bypassed and an appreciation of the anatomy of curved canals gained by using stiff stainless steel K-Files. ${ }^{11,21,24}$ The disadvantages include operator fatigue and hand fatigue, a longer operational time; ${ }^{25}$ the risk of canal irregularities with the use of larger file sizes; ${ }^{16}$ and increased apical extrusion of debris. ${ }^{26}$

\section{Stainless Steel K-Files Reciprocation}

The M4 safety hand piece (SybronEndo, Glendora, CA, USA) was developed so that stainless steel K-Files could be used in a reciprocating motion for glide path enlargement (Fig. 2). The hand piece features a $4: 1$ gear reduction, oscillates $30^{\circ}$ in both clockwise and counter-clockwise directions, in this manner replicating manual wrist watch winding. According to the manufacturer, this watch-winding motion keeps the file loose inside the canal, reduces torsional stress and metal fatigue, and permits safe negotiation while the operator controls the apical pressure. The NSK Ti-Max Ti35L 10:1 (Nakanishi Inc, Tokyo, Japan), Endo-Gripper (Moyco/ Union Broach; Montgomeryville, USA) and the NSK TEP-E10 R (Nakanishi Inc.) are similar to the M4 hand piece but with $45^{\circ}$ and $90^{\circ}$ horizontal rotational motions, respectively.

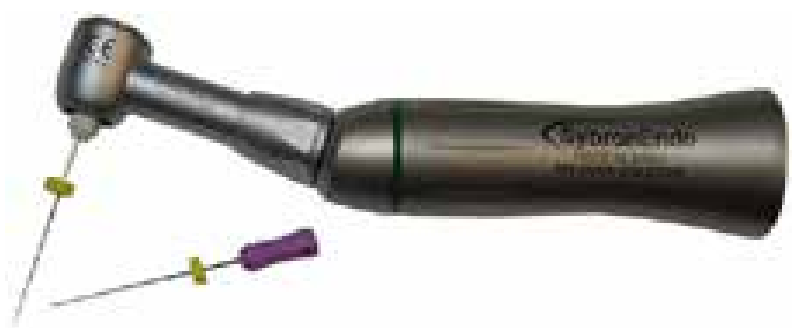

Figure 2. M4 Safety Reciprocating Hand Piece (SybronEndo) with a size 08 stainless steel K-File attached.

A study by Gambarini et al. compared the cyclic fatigue resistance between stainless steel K-Files used in a reciprocating motion and NiTi PathFile rotary instruments in artificial curved canals. ${ }^{27}$ The aim of their study was to evaluate whether stainless steel instruments could benefit from a reciprocating motion during their enlargement of the glide path, given that that reciprocation can improve fatigue resistance of NiTi instruments. The stainless steel K-Files used with the M4 hand piece showed a significantly greater resistance to cyclic fatigue in comparison with the NiTi rotary PathFiles.

Clinically, reciprocation is used after the canal has been negotiated to the working length by hand and with the use of a small-size K-File. Reciprocation proceeds with the first file that binds at working length. Reciprocation is useful for the early enlargement of calcified canals and the elimination of iatrogenic ledges. ${ }^{28}$ Once the stainless steel K-File can negotiate around the ledge, it is left in place and reciprocated, as suggested by Mounce. ${ }^{28}$

The advantages of using a stainless steel K-File in a reciprocating hand piece for glide path enlargement include a reduction in preparation time; reduced operator and hand fatigue; and reduced risk of instrument separation compared with rotary NiTi methods. ${ }^{29}$ The disadvantages include the need for a dedicated hand piece; the risk of apical transportation with files larger than a $15 \mathrm{~K}$-File; ${ }^{19}$ the risk of excess dentine removal as a result of the clinician instrumenting the canal for longer than necessary; ${ }^{30}$ the risk of apical extrusion of debris if the hand piece is forced apically; ${ }^{29}$ and decreased tactile sensation.

\section{Rotary Glide Path Instruments}

\subsection{PathFiles (Dentsply Sirona)}

In 2009, Dentsply Sirona introduced a three-file rotary NiTi system specifically for glide path enlargement. Each file has a taper of $2 \%$ and exhibits a square cross-section. These features, according to the manufacturer, ensure flexibility, improved cutting efficiency, and render these files more resistant to cyclic fatigue. The tip of each file is non-cutting, which reduces the risk of ledge formation. PathFile no. 1 (purple) has an ISO 13 tip size, PathFile no.2 (white) ISO 16 tip size and PathFile no.3 (yellow) has an ISO 19 tip size (Fig. 3). The gradual increase in tip size facilitates progression of the files. The manufacturer suggests using PathFile no.1 only after a size 10 stainless steel K-File has been used to explore the root canal to working length. ${ }^{25}$

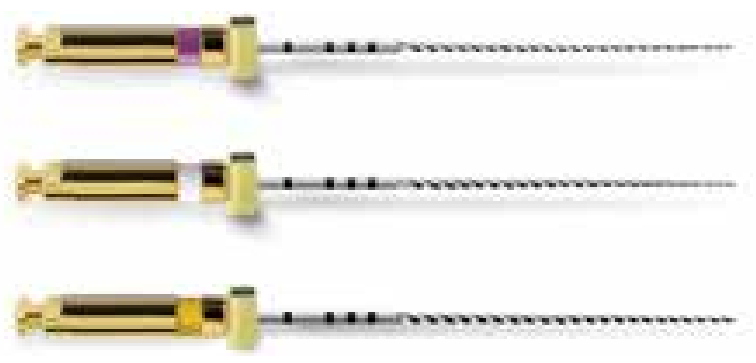

Figure 3. PathFile no.1 (purple), PathFile no.2 (white) and PathFile no.3 (yellow) (Dentsply Sirona).

There are numerous studies on the efficacy of PathFiles. Berutti et al. have shown that PathFiles maintain the original canal anatomy with less modification of canal curvature and fewer canal aberrations than does manual glide path enlargement performed with stainless steel K-Files. ${ }^{25}$ Pasqualini et al. used micro-computed tomography (micro-CT) to examine curved root canals where glide paths were prepared to full working length with the use of PathFiles and stainless steel K-Files. ${ }^{31}$ 
These researchers concluded that PathFiles have a higher root canal centering ability, cause fewer modifications of the canal curvature and fewer canal aberrations and, therefore, maintain the original canal shape considerably better than do stainless steel K-Files. In 2014 Nakagawa et al. studied the flexibility and torsional resistances of rotary NiTi PathFile, RaCe ISO 10 (FKG Dentaire, La Chaux-de-Fonds, Switzerland), ScoutRaCe (FKG Dentaire) and stainless steel hand K-Files. ${ }^{32}$

The results of this study demonstrated that the $\mathrm{NiTi}$ rotary glide path enlargement files were more effective at enlarging the glide path with fewer aberrant modifications to canal anatomy. PathFiles were shown to be the most flexible and the least torque resistant compared with ScoutRaCe and RaCe ISO 10 instruments. A study examining the influence of a glide path on canal curvature and axis modification after instrumentation with WaveOne Primary reciprocating files (Dentsply Sirona) showed significantly fewer canal modifications when WaveOne was used after glide path enlargement. ${ }^{33}$

\subsection{RaCe ISO 10 (FKG Dentaire)}

RaCe ISO 10 (FKG Dentaire) (Fig. 4) is a three-file system with progressively increasing tapers: 2\% (yellow ring), $4 \%$ (red ring) and 6\% (blue ring). All have the same apical diameter of $0.1 \mathrm{~mm}$. These files have been indicated for constricted obliterated canals and for abrupt coronal curvatures. ${ }^{34}$

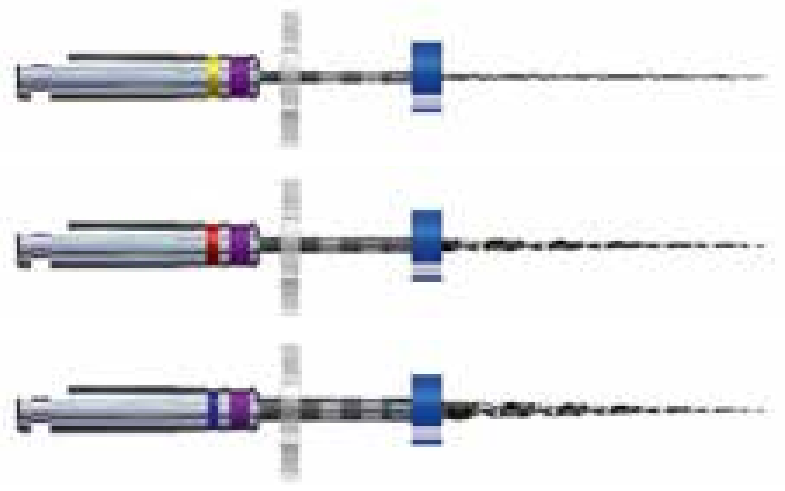

Figure 4. RaCe ISO 10 (FKG Dentaire) 2\% (yellow), 4\% (red) and 6\% (blue) tapered files.

\subsection{ScoutRaCe (FKG Dentaire)}

ScoutRaCe (FKG Dentaire) (Fig. 5) is a two-file system with each file exhibiting a $2 \%$ taper, a triangular cross section, alternating cutting edges and a non-cutting tip. They are available in ISO tip size 10 (purple), 15 (white) and 20 (yellow) and are used in sequence following initial canal exploration with a size 06 or $08 \mathrm{~K}$-File to working length. ${ }^{35}$

Ajuz et al. examined changes in canal curvature and incidence of canal irregularities after glide path enlargement with stainless steel K-Files, PathFiles and ScoutRaCe files. ${ }^{36}$ PathFile instruments generated less modification of curvature and fewer canal aberrations. ScoutRaCe, however, showed significantly better performance in shaping double-curved canals. A study by Lopes et al. compared the mechanical properties of C-Pilot (VDW), PathFile (Dentsply Sirona), and ScoutRaCe. ${ }^{37}$
PathFile instruments showed the highest resistance to cyclic fatigue, and ScoutRaCe files exhibited the highest angular deflection to fracture.

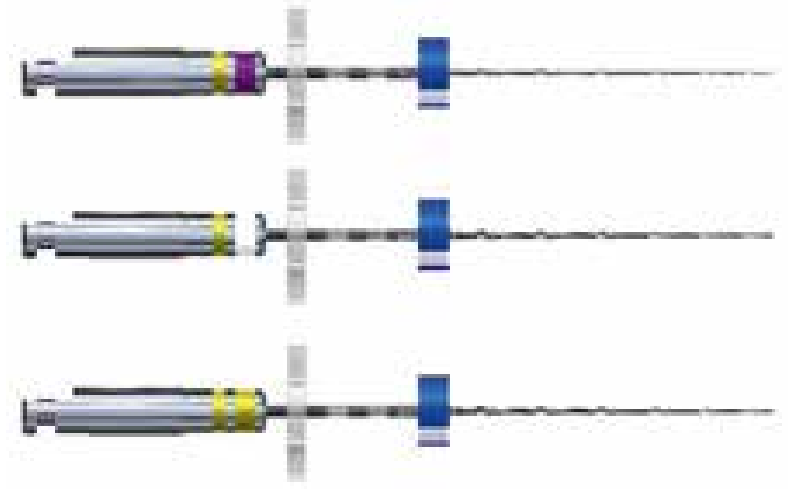

Figure 5. ScoutRaCe files (FKG Dentaire) ISO size 10 (purple), ISO size 15 (white) and ISO size 20 (yellow).

\subsection{G-Files (Micro-Mega, Besançon, France)}

The G-File system (Micro-Mega) consists of two files: the G1 file (red ring) with an ISO 12 tip size; and the G2 file (white ring) with an ISO 17 tip size (Fig. 6). The files have a $3 \%$ taper along the length, an evolving cross section that varies along the instrument, and non-cutting asymmetrical tips to aid in the progression of the file. The cross section has blades on three different radii to aid in the removal of debris and to reduce torsion. The manufacturer recommends their use after a size 10 hand file has been used to explore the canal to working length.

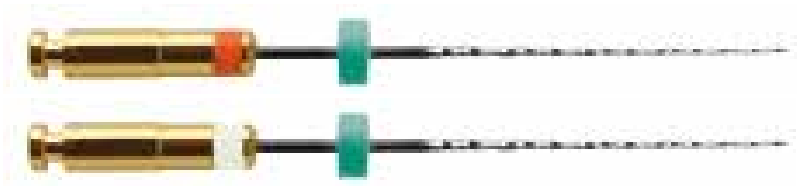

Figure 6. G-Files (Micro-Mega) G1 (red ring) and G2 (white ring).

\subsection{ProGlider (Dentsply Sirona)}

The ProGlider (Dentsply Sirona) (Fig. 7) is single mechanical glide path file manufactured using Memory nickel-titanium wire (M-Wire). M-Wire is constructed by thermos-mechanically treating NiTi to increase flexibility and resistance to cyclic fatigue. According to Johnson et al. this process makes M-Wire files almost $400 \%$ more resistant to cyclic fatigue than conventional $\mathrm{NiTi}$ files and, in this way, decreases the risk of file fracture. ${ }^{38}$

\section{nes}

Figure 7. ProGlider file (Dentsply Sirona).

The ProGlider file has a square cross section with a diameter of $0.16 \mathrm{~mm}$ at D0 and $0.82 \mathrm{~mm}$ at D16 and is progressively tapered from $2 \%$ to $8 \%$ over its length. According to its manufacturers, the file ensures a controlled, smooth, inward-cutting action that produces a smoother glide path. A small-size stainless steel K-File is initially used to scout, expand, and refine the internal walls of the canal. Once the canal can be manually reproduced, the single ProGlider file may be used to expand the working width in preparation for shaping procedures. ${ }^{39}$ 
A study by Van der Vyver, Paleker and Jonker compared the preparation times of glide path enlargement in plastic blocks, using stainless steel K-files, PathFiles (Dentsply Sirona), X-Plorer files (Clinician's Choice Dental Products Inc., New Milford, USA) and the single ProGlider file. ${ }^{40}$ The ProGlider file demonstrated significantly shorter glide path enlargement times with a mean preparation time of 11.3 seconds.

A more recent study compared the preparation times of glide path enlargement using stainless steel K-Files, G-Files (Micro-Mega, Besançon, France) and the single ProGlider file in curved mesial canals of mandibular molars. ${ }^{41}$ The ProGlider file and G-Files demonstrated significantly shorter glide path enlargement times with a mean preparation time of 27.95 and 41.87 seconds respectively. K-Files recorded a mean preparation time of 74.92 seconds. In this study by Paleker and Van der Vyver, micro-CT was used to compare the centering ability and apical canal transportation of these three file groups. Both the NiTi rotary glide path enlargement systems used here exhibited significantly less apical canal transportation than did the stainless steel K-files. The ProGlider file, however, exhibited a superior centering ability to that of both stainless steel K-Files and NiTi G-Files at the point of maximum curvature.

In 2014, Elnaghy and Elsaka used Cone Beam Computed Tomography (CBCT) imaging to compare the volume of removed dentine, transportation, and the centering ability of the ProTaper NEXT (Dentsply Sirona) system with and without glide path enlargement. ${ }^{3}$ The authors examined transportation values at 3-, 5-, and $7 \mathrm{~mm}$ levels. Their results showed significantly reduced mean transportation values at the $3 \mathrm{~mm}$ - and $5 \mathrm{~mm}$ level in the ProGlider-ProTaper NEXT group. The conclusion was reached that using this method resulted in better performance with fewer canal aberrations than instrumentation performed with PathFile-ProTaper NEXT or ProTaper Next only.

\subsection{One G (Micro-Mega)}

The One $G$ instrument (Micro-Mega) was launched in 2015 as a single file system for glide path enlargement. This NiTi rotary glide path file has a 3\% taper with three cutting edges situated on three different radii relative to the canal axis, which, according to the manufacturers, enhances the cutting action and allows for more space for debris elimination. The One G instrument has an ISO size 14 non-cutting tip that reduces the risk of ledge formation (Fig. 8) and a variable pitch between the cutting edges that is said to limit the screwing effect.

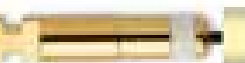

Figure 8. One G file (Micro-Mega).

Ha et al. compared the One G prototype with the G2 file (Micro-Mega) and found that One $G$ had a higher cyclic fatigue resistance. ${ }^{42}$ These authors concluded that the increased fatigue resistance and flexibility might enable maintenance of the original canal anatomy during glide path enlargement, as well as a reduced risk of ledge formation or transportation.
The minimised contact area from the shaft of 3\% taper was reported as possibly reducing the torque during instrumentation.

\subsection{X-Plorer Canal Navigation NiTi Files (Clinician's Choice Dental Products Inc., New Milford, USA)}

The X-Plorer Canal Navigation NiTi Files (Clinician's Choice Dental Products Inc.) (Fig. 9) consists of four instruments, available with distinctive cutting surfaces, tapers and cross-sections. The cutting surface of each file is limited to the apical $10 \mathrm{~mm}$ of the file. This feature decreases torsion and contact with the surrounding surface and, perhaps conversely, increases tactile feedback.

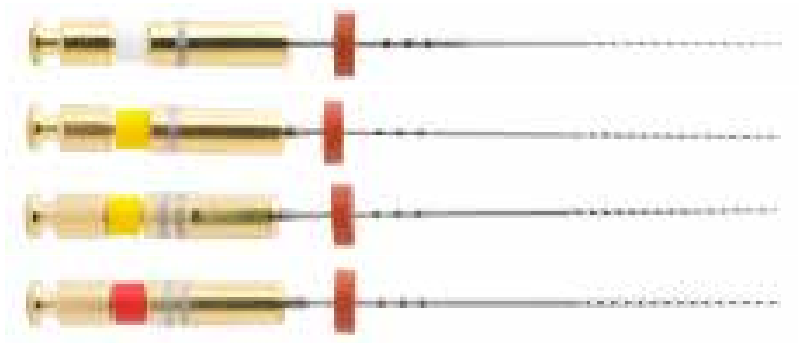

Figure 9. X-Plorer Canal Navigation NiTi Files (Clinician's Choice Dental Products Inc.) ISO 15 tip (white ring, marked 01), ISO 20 tip (yellow ring, marked 01), ISO 20 tip (yellow ring, marked 02), and ISO 25 tip (red ring, marked 02).

The manufacturer recommends using the X-Plorer series after a size 08 or size 10 stainless steel K-File has been used to penetrate the canal to working length. The first X-Plorer file has an ISO 15 tip size and a 1\% taper with a triangular cross section. The second has an ISO 20 tip size with a $1 \%$ taper and square cross section. The third has an ISO 20 tip size with a $2 \%$ taper and square cross section. The fourth has an ISO 25 tip size and a $2 \%$ taper with, again, a square cross section. The reduced taper increases flexibility and facilitates apical progression of the files. The X-Plorer files are available as rotary and hand files and have non-cutting tips each with a tip angle of $75^{\circ} . .^{15}$ Recently, a fourth file was introduced specifically for both clinicians who prefer to establish a working length up to a size 25 and those who want to have a larger diameter at working length before using rotary shaping files in tiny canals.

\section{Reciprocating Glide Path Instruments}

\subsection{WaveOne Gold Glider (Dentsply Sirona)}

The WaveOne Gold Glider (Dentsply Sirona) (Fig. 10) was launched in 2017. The file is a reciprocating NiTi file designed for glide path enlargement prior to shaping canals with a Primary WaveOne Gold instruments.

The WaveOne Gold Glider is a single-use sterile instrument and re-use is not allowed. The file has an ISO size 15 tip size with a variable taper of between $2 \%$ (D0) and $6 \%$ (D16) and a parallelogram shaped cross sectional design. The tip of the file is semi-active and the active cutting flute length is $16 \mathrm{~mm}$.

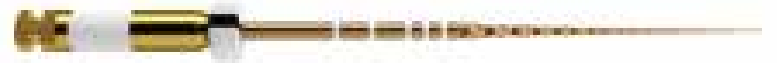

Figure 10. WaveOne Gold Glider (Dentsply Sirona). 
The manufacture of the WaveOne Gold Glider entails the use of NiTi wire subjected to a post-manufacturing thermal process. During this process, a new phasetransition point between martensite and austenite is identified in order to produce a file with super-elastic $\mathrm{NiTi}$ metal properties. This process gives the file a gold finish and renders it more flexible and more resistant to cyclic fatigue compared with conventional $\mathrm{NiTi}$ and M-Wire alloys. ${ }^{43}$

\subsection{R-Pilot (VDW, Munich, Germany)}

The R-Pilot instrument (VDW) (Fig. 11) is a glide path instrument manufactured from $\mathrm{M}$-Wire and is used in reciprocating motion to prepare the root canal system before the shaping with a rotary or a reciprocating instrument. The R-Pilot instrument has a constant taper of $4 \%$, an ISO tip size of 12.5 and an s-shaped cross section. It is a single-use instrument designed for use in no more than one molar.

The R-Pilot instrument can be used only in a reciprocating motion with a designated drive system that uses the original Reciproc (VDW) settings. Failure to do so, according to the manufacturers, can lead to instrument fracture and misuse. The instrument is not recommended for use in canals with abrupt apical curvatures in the apical region.

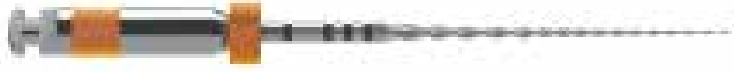

Figure 11. R-Pilot (VDW).

\section{CASE REPORT}

A patient, a 70-year-old male, reported with irreversible pulpitis affecting his maxillary first left molar. The tooth provided an abutment for a three-unit zirconia bridge.

A periapical radiograph revealed possible curvatures in the mesiobuccal and distobuccal root canals (Figure 12). It was decided with the consent of the patient to take a limited field of view CBCT scan to explore the anatomy of this tooth. The scan revealed in the axial plane three root canal systems, and in the sagittal plane it was evident that there were indeed severe root curvatures present in the mesiobuccal and distobuccal root canal systems. It was decided to undertake a more in-depth investigation regarding this complex anatomy, using the 3D Endo Software (Dentsply Sirona).

The data of the limited field of view CBCT scan was exported as a DICOM files and imported into the 3D Endo Software. The 3D Endo software confirmed severe curvatures in the two mesiobuccal root canals and an apical curvature in the distobuccal root canal. The software projects the proposed root canal instruments into the canals (Figure 13), allowing the operator to visualize the internal anatomy of the root canals. The image may be rotated in $3 D$ to alert the operator to the angles and directions of curvatures in the root canal systems. Note the severe midroot curvatures in the two mesiobuccal root canals and in the apical part of the distobuccal root canal.

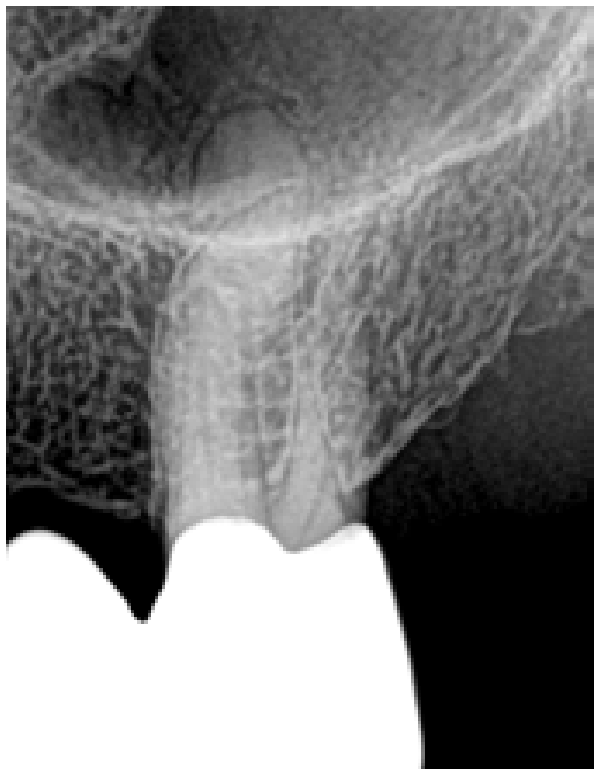

Figure 12. Preoperative periapical radiograph.

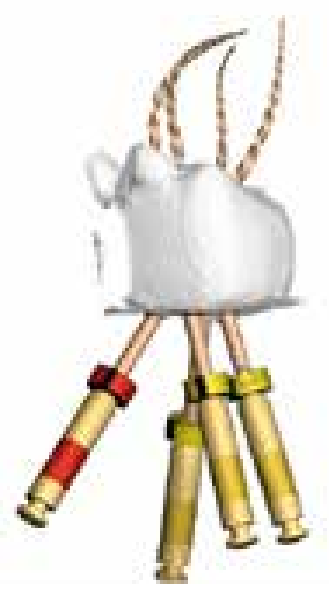

Figure 13. The 3D Endo Software projects the proposed root canal instruments into the canals. Note the severe midroot curvatures in the two mesiobuccal root canals and apical part of the distobuccal root canal.

At a following visit the tooth was anaesthetized, a rubber dam placed, and an access cavity was prepared.

The canals were located under magnification.

\section{Canal negotiation and glide path preparation}

The pulp chamber was filled with Glyde Root Canal Conditioner (Dentsply Sirona) and canal negotiation was initiated with a pre-curved size $08 \mathrm{~K}$-File. It was possible to negotiate the palatal and distobuccal canals to patency.

It was only possible to negotiate the mesiobuccal canal to approximately two thirds down the length of the mesiobuccal root canals before resistance was met (Figure 14a). It was decided to flare the coronal aspect of the canal with a WaveOne Gold Glider (Figure 14b). The larger coronal flare of the canals allowed a size 08 K-File to progress to patency (Figure 14c). Working length measurements were obtained from an electronic apex locator and confirmed radiographically (Figure 15).

The size $08 \mathrm{~K}$-File fitted very tightly into the root canals and it was decided to prepare a reproducible glide path for each root canal system with the size 08 K-File in a M4 Reciprocating hand piece (Sybron Endo) (Figure 16a), followed by repetitive instrumentation to make a size $10 \mathrm{~K}$-File super loose" (Figure 16b). Thereafter, a WaveOne Gold Glider (Dentsply Sirona) was used in reciprocating motion to expand the glide path up to full working length (Figure 16c). 


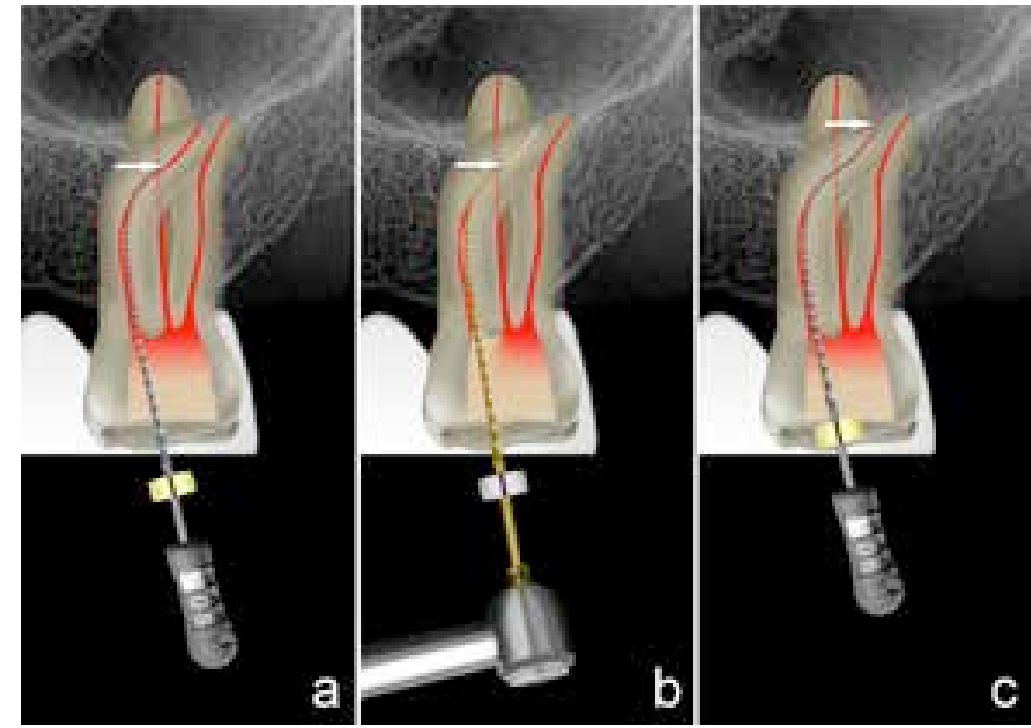

Figure 14. (a) It was only possible to negotiate the mesiobuccal canals to approximately two thirds of the full length with a size $08 \mathrm{~K}$-File before resistance was met; (b) coronal aspects of the mesiobuccal canals were flared with a WaveOne Gold Glider; (c) Increased coronal flare of the canals allowed a size $08 \mathrm{~K}$-File to progress to full length and patency.
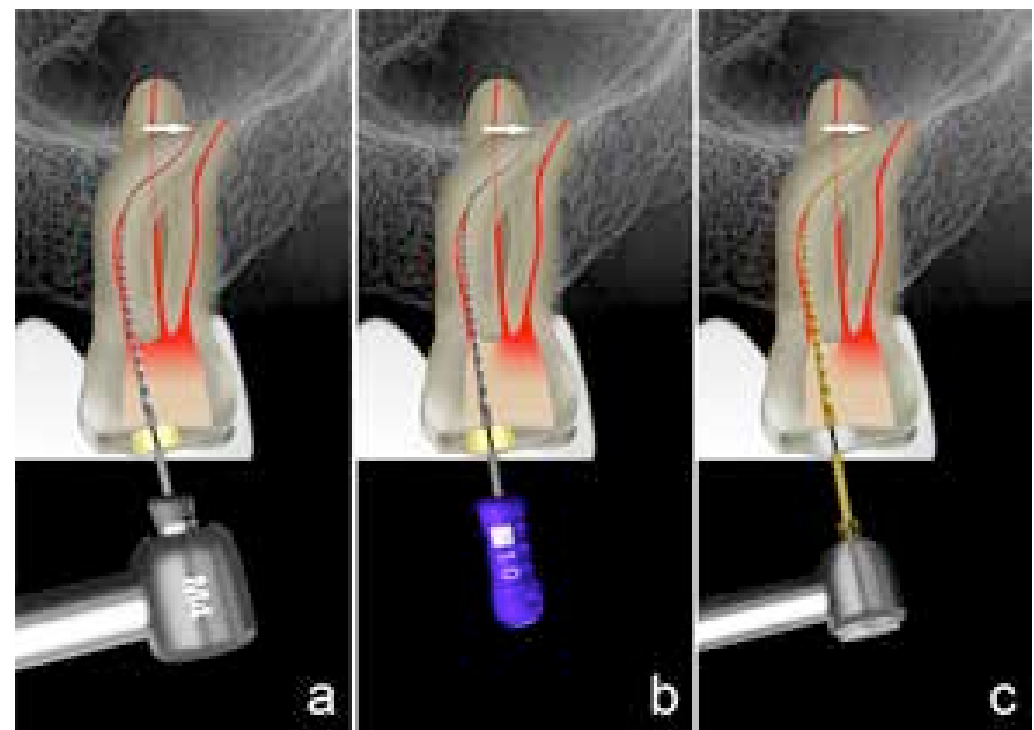

Figure 16. (a) Size $08 \mathrm{~K}$-File in the M4 Reciprocating hand piece was used to initiate the preparation of a reproducible micro glide path; (b) size $10 \mathrm{~K}$-File was made "super loose" to complete the preparation of the reproducible micro glide path; (c) Wave One Gold Glider was used in a reciprocating motion to further the glide paths in all the root canals.

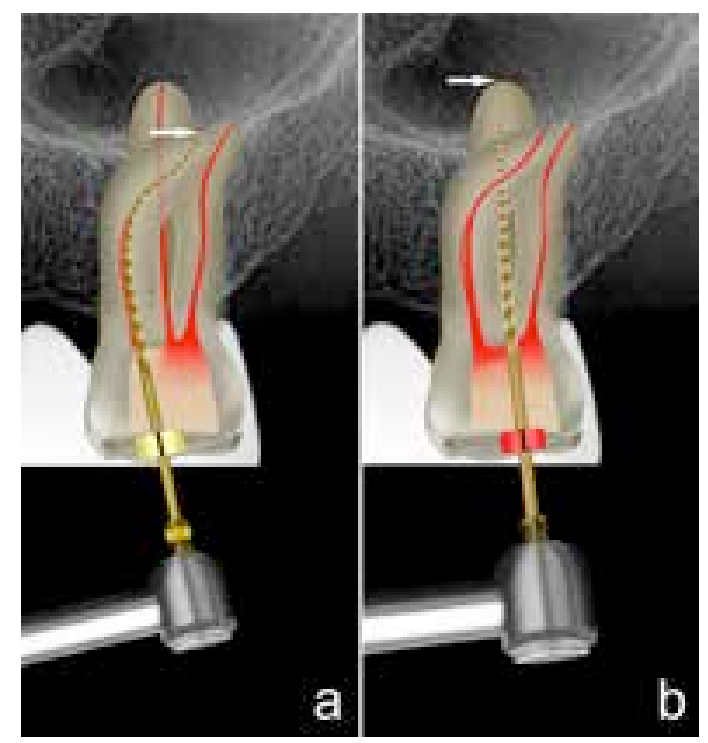

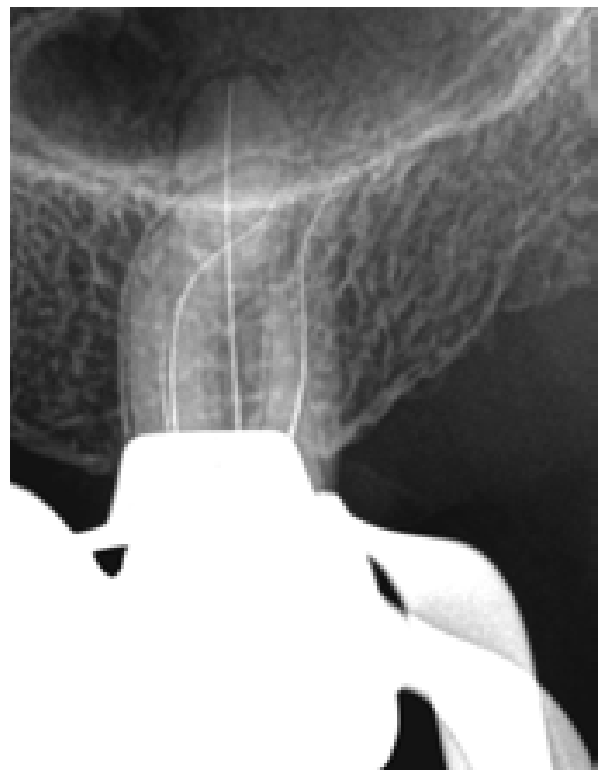

Figure 15. Length determination radiograph.

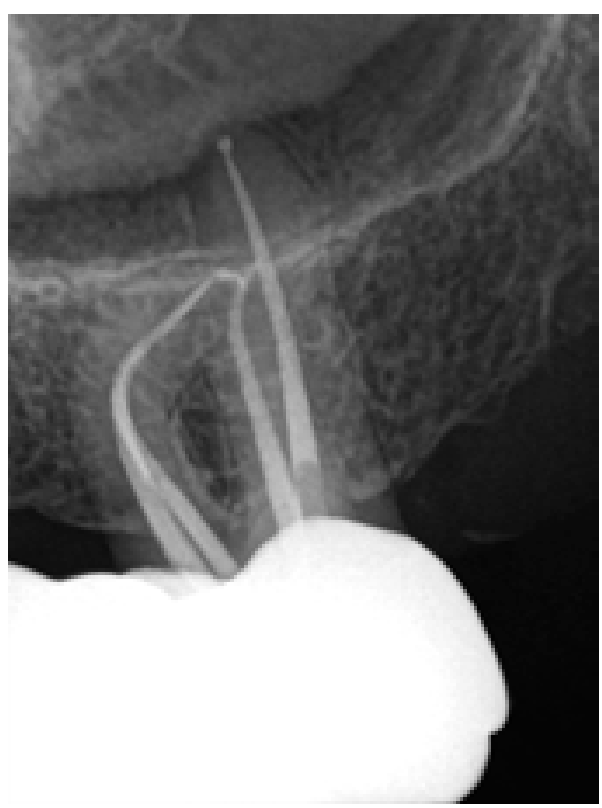

Figure 18. Periapical radiograph showing the final result after obturation. Note the severe curvature of the two mesiobuccal root canal systems.

\section{Root Canal Preparation, Irrigation and Obturation}

The two mesiobuccal and the distobuccal root canal systems were prepared with the Small Wave One Gold instrument (figure 17a) and the palatal canal was prepared with the Primary Wave One Gold instrument (Figure 17b).

After canal preparation, the canals were flooded with 17\% EDTA solution (Ultradent) and the solution activated for 1 minute with EDDY Endo Irrigation Tip (VDW) driven by an air scaler (Soniflex LUX 2000L, KAVO). Thereafter, final disinfection was achieved by activating $3.5 \%$ heated sodium hypochlorite for 3 minutes, again activated with the EDDY Endo Irrigation Tip.

Figure 17. Root canal preparation was done with the (a) Small WaveOne Gold instrument in the two mesiobuccal and distobuccal root canal systems (b) Primary WaveOne Gold instrument for the palatal root canal system. 
The canals were dried with paper points and obturated using matching gutta-percha points, Pulp Canal Sealer (Kerr) and the Calamus Dual Obturation Unit (Dentsply Sirona). Figure 18 shows the final result after obturation.

\section{CONCLUSION}

With the introduction of newer glide path systems (for example single file and reciprocating glide path systems) and the advancement in the metallurgic properties of these glide path instrumentation systems, the clinician is presented with the opportunity to enlarge and shape root canals systems more predictably, with a reduction in preparation time as well as a decrease in procedural aberrations.

\section{References}

1. West J. Endodontic update 2006. J Esthet Restor Dent. 2006;18:280-300.

2. Khatavkar R, Hegde V. Importance of patency in endodontics. Endodontology 2010;22:85-91.

3. Elnaghy A, Elsaka S. Evaluation of root canal transportation, centering ratio, and remaining dentin thickness associated with Protaper NEXT instruments with and without glide path. $J$ Endod. 2014;40(12):2053-6.

4. Kirchhoff A, Chu R, Mello I, Garzon A, Dos Santos M, Cunha R. Glide path management with single- and multiple-instrument rotary systems in curved canals: A micro-computed tomographic study. J Endod. 2015;41(11):1880-3.

5. De-Oliveira Alves V, Da Silveira Bueno C, Cunha R, Pinheiro S, Fontana C, De Martin A. Comparison among manual instruments and pathfile and two rotary instruments to create a glide path in the root canal preparation of curved canals. J Endod. 2012;38(1):117-20.

6. D'Amario M, Baldi M, Petricca R, De Angelis F, El Abed R, D'Arcangelo C. Evaluation of a new nickel-titanium system to create the glide path in root canal preparation of curved canals. J Endod. [Internet]. 2013;39(12):1581-4. Available from: http:// dx.doi.org/10.1016/j.joen.2013.06.037

7. Berutti E, Alovisi M, Pastorelli M, Al E. Energy consumption of ProTaper Next X1 after glide path with and PathFiles and ProGlider. J Endod. 2014;40:2015-8.

8. Elnaghy A, Elsaka S. Evaluation of the mechanical behaviour of PathFile and ProGlider pathfinding nickel - titanium rotary instruments. Int Endod J. 2015;894-901.

9. Ruddle C. Cleaning and shaping the root canal system. In: Cohen S, Burns R, editors. Pathways of the Pulp. $8^{\text {th }}$ ed. St Louis, Missouri: Mosby; 2002.

10. Gergi R, Rjeily J, Sader J, Naaman A. Comparison of canal transportation and centering ability of twisted files, PathfileProTaper system, and stainless steel hand K-files by using computed tomography. J Endod. 2010;36(5):904-7.

11. Berutti E, Negro A, Lendini M, Pasqualini D. Influence of manual preflaring and torque on the failure rate of ProTaper rotary instruments. J Endod. 2004;30(4):228-30.

12. Varela-Patiño P, Martin-Biedma B, Liébana C, Cantatore G, Bahillo $\mathrm{J}$. The influence of a manual glide path on the separation rate of NiTi rotary instruments. J Endod. 2005;31(2):114-6.

13. Ruddle C. Shaping complex canals: Clinical strategy and technique. Dent Today. 2014;33(11):1-8.

14. Roland D, Andelin W, Browning D, Hsu G, Torabinejad M. The effect of preflaring on the rates of separation for 0.04 taper nickel titanium rotary instruments. J Endod. 2002;28(7):543-5.

15. Nahmias Y, Cassim I, Glassman G. " Own the canal "- the importance of a reproducible glide path. Oral Heal J. 2013;(May):74-82.

16. West J. The endodontic glidepath: "secret to rotary safety." Dent Today. 2010;29(9):86-3.
17. Sathorn C, Palamara J, Messer H. A comparison of the effects of two canal preparation techniques on root fracture susceptibility and fracture pattern. J Endod. 2005;31:283-7.

18. Versluis $A$, Messer $H$, Pintado $M$. Changes in compaction stress distributions in roots resulting from canal preparation. Int Endod J. 2006;9:931-9.

19. Van der Vyver P. Creating a glide path for rotary NiTi instruments: Part one. Endod Prac. 2011;31:40-3.

20. Schilder $\mathrm{H}$. Cleaning and shaping the root canal. Dent Clin North Am. 1974;18:269-96.

21. Jerome C, Hanlon RJ. Identifying multiplanar root canal curvatures using stainless-steel instruments. J Endod. 2003;29:356-8

22. Mounce R. Endodontic K-files: invaluable endangered species or ready for the Smithsonian? Dent Today. 2005;24:102-4.

23. Cassim I, van der Vyver P. The importance of glide path preparation in endodontics: a consideration of instruments and literature. South African Dent J. 2013;68(7):322-7.

24. Young G, Parashos P, Messer $H$. The principles of techniques for cleaning root canals. Aust Dent J. 2007;52 (Supplement 1):52-63.

25. Berutti E, Cantatore G, Castellucci A, Chiandussi G, Pera F, Migliaretti $G$, et al. Use of nickel-titanium rotary PathFile to create the glide path: comparison with manual preflaring in simulated root canals. J Endod. 2009 Mar;35(3):408-12.

26. Greco K, Carmignani E, Cantatore G. A comparative study between manual and mechanic pre-flaring techniques. In: Paper presented to the Fifteenth Biennial Congress of the European Society of Endodontology. Rome, Italy; 2011. p. 14-7.

27. Gambarini G, Plotino G, Sannino G, Grande N, Giansiracusa A, Piasecki $L$, et al. Cyclic fatigue of instruments for endodontic glide path. Odontology. 2015;103(1):56-60.

28. Mounce R. Using hand files to their full capabilities: A new look at an old yet emerging technology. Autralasian Dent Pract. 2013;(June):4-9.

29. Kinsey B, Mounce R. Safe and efficient use of the M4 safety handpiece in endodontics. Roots 2008;4:36-40.

30. Wagner M, Barletta F, Reis Mde S, Mello L, Ferreira R, Fernandes A. NSK reciprocating handpiece: in vitro comparative analysis of dentin removal during root canal preparation by different operators. Braz Dent J. 2006;17(1):10-4.

31. Pasqualini D, Bianchi C, Paolino D, Mancini L, Cemenasco A, Cantatore $\mathrm{G}$, et al. Computed micro-tomographic evaluation of glide path with nickel-titanium rotary PathFile in maxillary first molars curved canals. J Endod. 2012;38(3):389-93.

32. Nakagawa R, Alves J, Buono V, Bahia M. Flexibility and torsional behaviour of rotary nickel-titanium PathFile, RaCe ISO 10, Scout RaCe and stainless steel K-File hand instruments. Int Endod J. 2014;47:290-7.

33. Berutti E, Paolino D, Chiandussi G, Alovisi M, Cantatore G, Castellucci A, et al. Root canal anatomy preservation of WaveOne reciprocating files with or without glide path. J Endod. 2012;38(1):101-4.

34. Debelian G, Trope M. Scouting the root canal with dedicated NiTi files. Roots. 2012;2:24-7.

35. Cassim I, Van der Vyver P. An in vitro comparison of different techniques for glide path preparation. J Dent Res. 2013;92:183-227.

36. Ajuz N, Armada L, Gonçalves L, Debelian G, Siqueira J. Glide path preparation in s-shaped canals with rotary pathfinding nickel-titanium instruments. J Endod [Internet]. 2013 Apr [cited 2014 Aug 27];39(4):534-7. Available from: http://www.ncbi.nlm.nih.gov/pubmed/23522552

37. Lopes H, Elias C, Siqueira JJ, Soares R, Souza L, Oliveira J, et al. Mechanical behavior of pathfinding endodontic instruments. J Endod. 2012;38:1417-1421.

38. Johnson E, Lloyd A, Kuttler S, Namerow K. Comparison between a novel nickel-titanium alloy and 508 nitinol on the cyclic fatigue life of Profile 25/.04 rotary instruments. J Endod. 2008;34(11):1406-9. 
39. Van der Vyver P. Proglider: clinical protocol. Clin Pract. 2014;(May):12-7.

40. Van der Vyver P, Paleker F, Jonker C. Comparison of preparation times of three different rotary glide path instrument systems. South African Dent J. 2015;70(4):146-9.

41. Paleker F, Van Der Vyver P. Glide path enlargement of mandibular molar canals by using K-files, the Proglider File, and G-Files: a comparative study of the of the preparation times. J Endod. 2017;43(4):609-12.

42. Ha J, Lee C, Kwak S, El Abed R, Ha D, Kim H.

Geometric optimization for development of glide path preparation nickel-titanium rotary instrument. J Endod [Internet]. 2015;41(6):916-9.Availablefrom:http://linkinghub.elsevier.com/ retrieve/pii/S0099239915000771

43. Webber J. Shaping canals with confidence: WaveOne GOLD single-file. Roots. 2015;1:34-40.

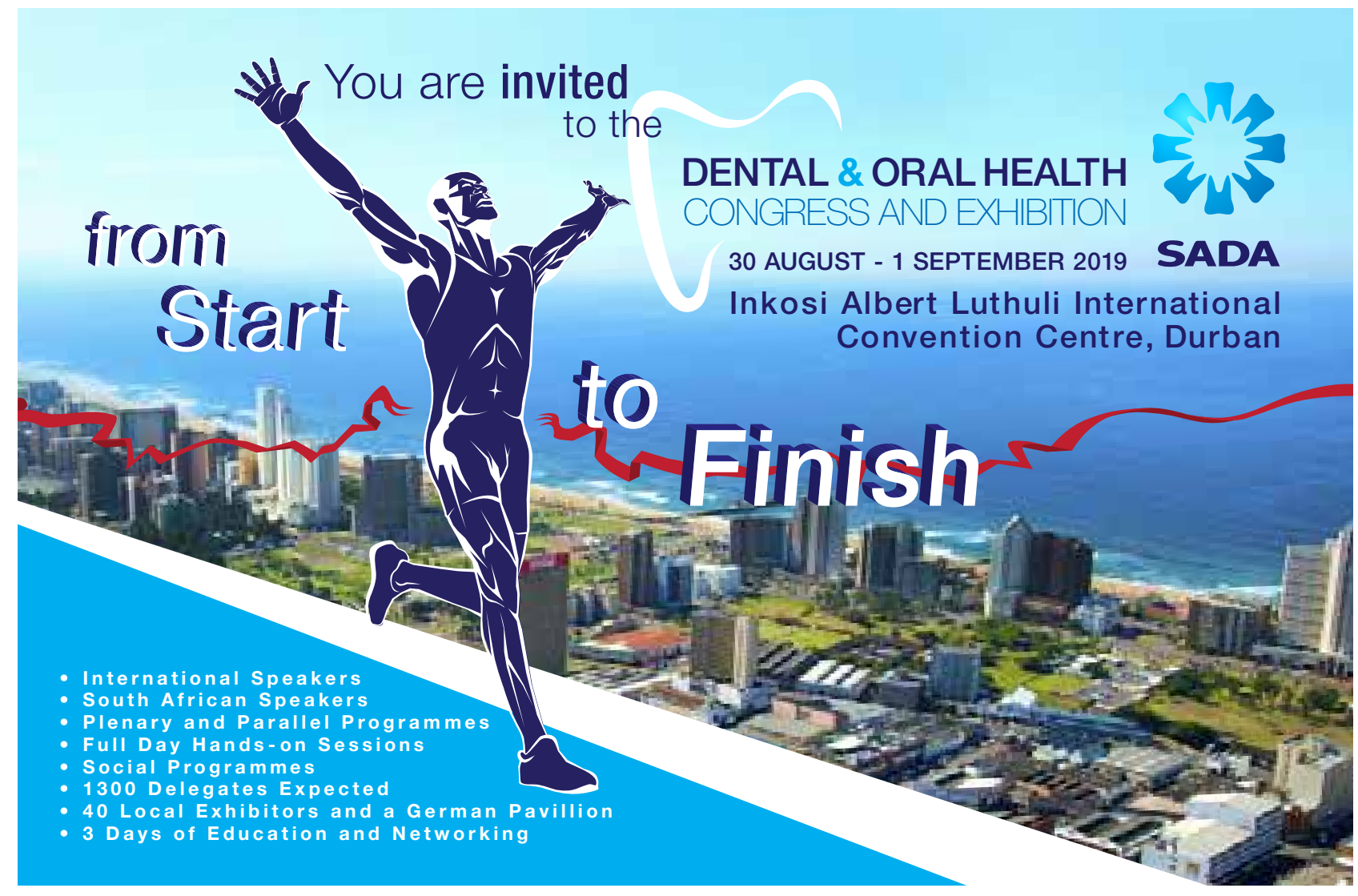

\section{Register for the SADA Dental \& Oral Health Congress and Exhibition on page 158}

For online registration and payment go to: www.sadacongress.co.za If not registering online please complete the registration form on page 158 and submit with your credit card details for singular transaction processing.

Send the completed registration form to SADA via Email: mvdlinde@sada.co.za, or Fax: +27 (0)86 6807390

\section{Online registration in 4 Easy Steps}

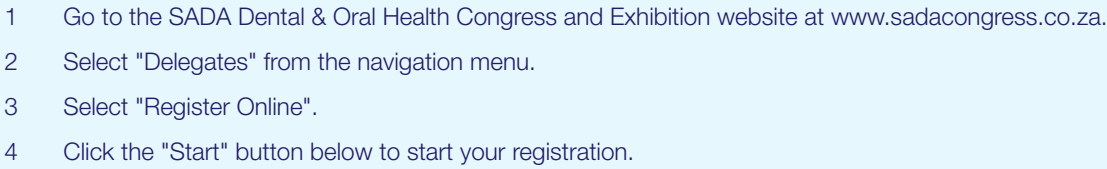

